\title{
Práticas escolares e desempenho acadêmico de alunos COM TDAH
}

\author{
Práticas escolares e TDAH \\ Maria das Graças Faustino Reis \\ Dulce Maria Pompêo de Camargo
}

\begin{abstract}
Resumo
Este artigo reporta resultados de trabalho de pesquisa que tem como objeto o estudo crítico e aprofundado sobre o TDAH (Transtorno de Déficit de Atenção/Hiperatividade) nos cursos de formação de professores no Ensino Superior, sob as suas variadas dimensões - social, cultural, pedagógica, biológica. A investigação focalizou cinco adultos com diagnóstico de TDAH. A metodologia utilizada foi o Estudo de Caso, desenvolvido a partir da História Oral como fonte de coleta de dados. Os resultados obtidos sugerem que o estudo proposto na pesquisa pode contribuir significativamente para o professor conhecer os determinantes do desempenho escolar de alunos com o transtorno, bem como orientá-lo na busca de parceria com outros profissionais - médicos e psicólogos, por exemplo - quando esta se fizer necessária.

Palavras-chave: ensino superior; formação de professores; TDAH.
\end{abstract}

\section{School practices and Academic performance of students with}

\begin{abstract}
This article reports the results from the research work which objects the critical and profound study about the ADHD (Attention Deficit/Hyperactivity Disorder) in the courses for teachers' development in College Education, under its various dimensions - social, cultural, pedagogical, biological. The investigation focused on five adults with diagnosis for ADHD. The methodology used was the Case Study, developed from the Oral History as a source of data. The results that were obtained suggest that the study, proposed in the research, may contribute significantly for the teachers to know determining factors of the school performance of students with this disorder, as well as to guide them in the search of partnership with other professionals - doctors and psychologists, for example - when such partnership becomes necessary.
\end{abstract}

Keywords: undergraduate education; teacher education; ADHD (Attention Deficit Disorder with Hyperactivity).

\section{Practicas escolares y rendimiento académico de alumnos con TDAH}

\section{Resumen}

Este artículo presenta los resultados de investigaciones que tienen como objetivo el estudio crítico y profundo sobre el TDAH (Trastorno de Déficit de Atención/Hiperactividad) en los cursos para formación profesores en la Enseñanza Secundaria, en varias de sus dimensiones - social, cultural, pedagógica, biológica. La investigación se concentró en cinco adultos con diagnóstico de TDAH. La metodología utilizada fue el Estudio de Caso, desarrollado a partir de la Historia Oral como fuente de cosecha de datos. Los resultados obtenidos sugieren que el estudio propuesto puede contribuir significativamente para que el profesor conozca los determinantes del rendimiento escolar de alumnos con ese trastorno, así como también orientarlos en la búsqueda por la compañía de otros profesionales - médicos y psicólogos, por ejemplo- cuando sea necesario.

Palabras clave: enseñanza superior; formación de profesores; TDAH. 


\section{Introdução}

Um dos principais problemas observados no processo pedagógico são os comportamentos inadequados de alguns alunos nas diversas atividades escolares. O despreparo dos docentes para lidar com os conflitos que surgem nas salas de aula também contribui para a configuração do quadro. Além disso, geralmente, a proposta educacional da escola prevê um único tipo de enquadramento dos alunos no processo pedagógico. Por não se adequarem ao padrão pedagógico convencional, é comum alunos com TDAH (Transtorno de Déficit de Atenção/Hiperatividade) reagirem negativamente, tornando-se inadequados.

Nos últimos anos, muito se tem ouvido falar em TDAH, mas poucos profissionais da área da Educação conhecem as dificuldades relacionadas à atenção, hiperatividade e impulsividade, vivenciadas por alguns alunos. Abordar esse assunto tem sido uma atividade desafiadora, seja por desconhecimento do problema pelas pessoas, pela descrença de que ele realmente exista, ou pela tendência de a literatura culpabilizar alguém. Ante o desafio, os argumentos vão desde a afirmação de que a escola não oferece condições positivas de aprendizagem para os alunos com TDAH, pois os conteúdos não são atraentes e os professores não sabem motivar as aulas, até o argumento de que a causa seja unicamente biológica, ou ainda, seja a falta de limites impostos pelas famílias.

Buscando entender as relações que permeiam o desempenho acadêmico dos alunos de que trata esta pesquisa $^{1}$, foi delimitado como objetivo: analisar as relações implicadas entre o aluno com TDAH e a prática docente, a partir da fala dos participantes cinco adultos com o diagnóstico de instabilidade de atenção, impulsividade e hiperatividade.

\section{Transtorno de Déficit de}

\section{Atenção/Hiperatividade (TDAH)}

De acordo com o Manual diagnóstico $e$ estatístico de transtornos mentais (DSM-IV) da Associação Americana de Psiquiatria, quarta edição (1994), o indivíduo com TDAH apresenta os seguintes sintomas:

- Seis (ou mais) sintomas de desatenção: freqüentemente deixa de prestar atenção a detalhes ou comete erros por descuido em atividades escolares, de trabalho ou outras; tem dificuldades para manter a atenção em tarefas ou atividades lúdicas; parece não escutar quando lhe dirigem a palavra; não segue instruções nem termina seus deveres escolares, tarefas domésticas ou deveres profissionais; tem dificuldade para organizar tarefas e atividades; evita envolver-se em tarefas que exijam esforço mental constante; perde coisas necessárias para tarefas ou atividades; é freqüentemente distraído por estímulos alheios à tarefa; apresenta esquecimento em atividades diárias.

\footnotetext{
1 Este estudo faz parte dos resultados obtidos em pesquisa de mestrado em Educação, cuja referência é REIS, M. G. F. A teia de significados das práticas escolares: Transtorno de Déficit de Atenção/Hiperatividade (TDAH) e formação de professores. Dissertação (Mestrado) - Pós-Graduação em Educação, Orientadora: Dulce Maria Pompêo de Camargo. Pontifícia Universidade Católica de Campinas. Campinas, 2006.
} 
- Seis (ou mais) sintomas de hiperatividade/impulsividade:

Hiperatividade: freqüentemente agita as mãos ou os pés ou se remexe na cadeira; abandona sua cadeira em sala de aula ou em outras situações nas quais se espera que permaneça sentado; corre ou escala em demasia, em situações nas quais isso é inapropriado; tem dificuldade para brincar ou se envolver silenciosamente em atividades de lazer; está freqüentemente "a mil" ou "a todo vapor"; fala em demasia.

Impulsividade: freqüentemente dá respostas precipitadas antes de as perguntas terem sido completadas; tem dificuldade para aguardar sua vez; interrompe ou intromete-se em assuntos de outros.

A incidência do TDAH é estimada em crianças e adultos, homens e mulheres, abrangendo todos os grupos étnicos, estratos sócio-econômicos, níveis de escolaridade e graus de inteligência. Apesar de ter sido considerado por muito tempo um transtorno exclusivo da infância e que seria superado no decorrer da adolescência, pesquisas atuais mostram que apenas um terço das pessoas com TDAH o supera e dois terços o apresentam por toda a vida (Hallowell \& Ratey, 1994/1999). Com o passar do tempo, alguns sintomas se modificam e outros permanecem estáveis. Além disso, os indivíduos tendem a moldar seus estilos de vida e a exercer profissões que se adaptam melhor às suas dificuldades pessoais (Mattos, Abreu \& Grevet, 2003).

A existência de diferentes quadros clínicos indica que o transtorno é bastante heterogêneo, apesar de ser caracterizado por sintomas de desatenção, hiperatividade e impulsividade. Barkley
(2002) afirma que a visão do problema como hiperatividade e falta de atenção tem se tornado limitada. Segundo o autor, a questão fundamental está na inabilidade de inibir o comportamento. Para explicar a sua teoria, ele se apoiou nos estudos de Jacob Bronowski sobre a habilidade que a espécie humana tem em esperar por períodos de tempo mais longos do que outras espécies antes de responder a estímulos. Barkley concorda com as quatro habilidades mentais estudadas por Bronowski, que nos permitem impor um atraso entre uma mensagem e nossa reação a ela, e acrescenta mais uma entre a terceira e a quarta: criar um senso de passado e, deste, um senso de futuro; falar a nós mesmos e usar esse discurso para controlar o próprio comportamento; separar emoções de informações frente à nossa avaliação de eventos; interiorizar emoções e usá-las na criação de motivação interna para dirigir o comportamento em busca de objetivos (contribuição de Barkley); quebrar em partes as informações ou mensagens que chegam e, então, recombinar essas partes em novas mensagens de saída ou respostas (análise e síntese).

Barkley acredita que as pessoas com o transtorno apresentem problemas nessas cinco habilidades mentais, que, anteriormente (1997), ele já havia denominado funções executivas. Mattos, Saboya, Kaefer, Knijnik e Soncini (2003) também entendem o problema como uma síndrome disexecutiva por considerarem que o principal comprometimento decorrente do TDAH é o das funções executivas. O sistema de controle executivo é responsável por recrutar e extrair informações de diversos outros sistemas cerebrais. As funções executivas compreendem uma classe de atividades 
altamente sofisticadas que, em conjunto, englobam todos os processos responsáveis por focalizar, direcionar, regular, gerenciar e integrar funções cognitivas, emoções e comportamentos. Elas são responsáveis pela realização de tarefas simples de rotina e, principalmente, pela solução ativa de problemas novos.

\section{Método}

Como metodologia de investigação, optou-se pelo Estudo de Caso, dada a possibilidade de esse tipo de pesquisa qualitativa permitir uma análise aprofundada do objeto de estudo, bem como dos sujeitos envolvidos. Dentre as opções de trabalho com o Estudo de Caso, elegeu-se a História Oral como fonte de coleta de dados. Esta, segundo Alberti (2004), é um método de pesquisa "que privilegia a realização de entrevistas com pessoas que participaram de, ou testemunharam, acontecimentos, conjunturas, visões de mundo, como forma de se aproximar do objeto de estudo" (p. 18).

\section{Participantes}

Contou-se com a ajuda de profissionais da área da Saúde - médicos e psicólogos - na busca de possíveis participantes da pesquisa, que foram escolhidos de acordo com o interesse e o consentimento dos mesmos. Selecionou-se cinco adultos com diagnóstico de TDAH, feito na infância ou não - mas que, neste caso, sofreram os seus efeitos: Cláudia, Paulo, Sandra, Thaís e Tânia ${ }^{2}$. Outro critério utilizado na seleção dos participantes foi estarem cursando o Ensino Superior ou já o terem concluído.

\section{Material}

Os materiais utilizados foram: questionário com questões fechadas sobre os dados pessoais e sócioculturais dos entrevistados, sobre a formação acadêmica e o diagnóstico do TDAH; entrevista semi-estruturada.

\section{Procedimento}

Antes das entrevistas, a metodologia e os objetivos foram esclarecidos aos entrevistados, ressaltando a importância de cada um na pesquisa. Durante as entrevistas, realizadas individualmente, eles falaram sobre a trajetória escolar de cada um, apontando: - em que fase da escolaridade ocorreu o diagnóstico do TDAH; - como foi a passagem pelos ensinos Fundamental, Médio e Superior; - o que fizeram (e fazem) para superar as dificuldades decorrentes do transtorno. Além do Levantamento dessas informações, foram formuladas outras questões, quando necessárias. Todos os entrevistados declararam-se diagnosticados com TDAH, com predominância do tipo hiperativo, sendo que o diagnóstico foi feito por médicos e/ou psicólogos.

Cada entrevista durou, em média, 45 minutos. A transcrição e a textualização das falas foram executadas pela pesquisadora. Na textualização, foi feita apenas a adequação gramatical, foram mantidas as interrupções de pensamento, as mudanças de foco temático e as posteriores

\footnotetext{
${ }^{2}$ Os nomes são fictícios.
} 
retomadas, por julgar importantes na análise que seria empreendida e pela freqüência da ocorrência.

\section{Resultados e Discussão}

A pesquisa configurou-se como possibilidade de reflexão sobre as práticas escolares relacionadas ao TDAH. Seria muito simplista a idéia de que falhas na formação de professores nos cursos de Ensino Superior sejam as únicas causas das dificuldades encontradas pelos alunos com o transtorno. No entanto, os professores são os sujeitos que, diretamente, podem interferir na aprendizagem, fazer a mediação entre os relacionamentos presentes no ambiente escolar e perceber quando há necessidade de solicitação de avaliação médica e/ou psicológica. Por isso, na formação de professores, deve-se ressaltar a importância de o professor conhecer os determinantes do desempenho escolar de seus alunos, bem como refletir sobre a participação da escola frente ao problema.

Todos os entrevistados citaram problemas escolares ocorridos, principalmente, no Ensino Fundamental e Médio, derivados do desconhecimento do TDAH pelos professores e pela falta de aproveitamento das características positivas do transtorno. No Ensino Superior, sentiram (sentem) menos dificuldades, por já terem descoberto maneiras de superar os obstáculos decorrentes de instabilidade da atenção, impulsividade e/ou hiperatividade; pela compreensão dos professores; ou mesmo, segundo uma entrevistada, por causa de pouca exigência feita aos alunos. As suas falas revelam lacunas na formação de professores e apontam caminhos para a reflexão do significado das práticas escolares. No estudo sobre a influência dessas práticas na aprendizagem e no comportamento de Cláudia, Paulo, Sandra, Thaís e Tânia, destacamos os tópicos "dificuldades acadêmicas" e "formação de professores".

\section{Dificuldades Acadêmicas}

Embora Sandra e Cláudia tivessem recebido tratamento medicamentoso na infância, sentiram dificuldades semelhantes às de Paulo, Tânia e Thaís, que só tiveram o diagnóstico do TDAH na vida adulta. Uma, por causa da dificuldade do diagnóstico correto, a outra, pela descontinuidade do tratamento. Os principais problemas apontados pelos entrevistados estão relacionados a: leitura e escrita, falta de dinamismo nas aulas, hiperatividade, avaliação de conteúdos escolares, indisciplina e agressividade, relacionamentos, autoestima, diversidade humana.

Quatro entrevistados tiveram alguma dificuldade relacionada à leitura e/ou à escrita Durante a escolaridade, por falta de concentração ou por não gostarem de ler. Em “eu sei o que é, mas eu não sei passar no papel" (Cláudia) e em "ler algum texto para depois dele partir para alguma outra coisa", há sinais de comprometimento das funções executivas, especificamente, a análise-síntese (Barkley 2002; Mattos \& cols., 2003). Apesar de o trabalho com a leitura e a escrita ser muito árduo para alunos com TDAH, é essencial para a sobrevivência na atual sociedade, pois esta requer o desenvolvimento/uso de competências cognitivas superiores, como além de análise e síntese - "rapidez de resposta, comunicação clara e precisa, interpretação e uso de diferentes formas de linguagem, capacidade para 
trabalhar em grupo, gerenciar processos para atingir metas, trabalhar com prioridades (...)" (Kuenzer, 2002, p.18).

Nas entrevistas, a monotonia das aulas é apontada como um elemento complicador para alunos com TDAH. Paulo diz que sempre teve dificuldades escolares, principalmente, até a quarta série do Ensino Fundamental. A recusa em fazer atividades pouco interessantes causava-lhe problemas. Tânia diz que não conseguia ficar quieta na sala e que nunca prestou muita atenção às aulas. Cláudia acredita que apresentou poucos sintomas do TDAH nas primeiras séries escolares porque as aulas eram dinâmicas. Outra explicação dada por ela é que até o início do segundo ciclo do Ensino Fundamental fazia uso de medicação. É provável que, também por isso, só tenha percebido obstáculos à aprendizagem após essa fase da escolaridade, quando abandonou o tratamento medicamentoso. Para Barkley (2002), durante atividades realizadas em grupo, a atenção dos alunos "pode ser melhorada com um estilo de aula mais entusiasmado, breve e que permita a participação ativa da criança” (p. 244). Segundo o autor, freqüentemente, alunos com TDAH têm notas menores nas avaliações e apresentam mais repetências de série, por não conseguirem fazer o mesmo trabalho escolar que outros alunos sem TDAH fazem. Na nossa pesquisa, Cláudia ressalta que sentia mais dificuldades nas avaliações do que durante as aulas. Em seguida, ela explica que o problema era a determinação de um tempo para a resolução dos exercícios de uma prova. O medo de não conseguir terminar a avaliação no tempo previsto, aliado à confusão que fazia com os conteúdos estudados, contribuía para os erros.
Sandra recorda-se de que a partir da primeira série do Ensino Fundamental passou a ter problemas relacionados ao medo de ser avaliada.

Tânia critica o tipo de escola em que estudou e aponta que o estilo pedagógico adotado pelo professor pode dificultar a sua compreensão sobre a inquietude de alguns alunos. Tonelotto (2003) explica que um aspecto que contribui para as dificuldades experimentadas por crianças com TDAH é a expectativa de que elas correspondam "a contento a um ambiente escolar que por si só é muito exigente" (p. 209). Já Aquino (2003) argumenta que se a indisciplina denuncia uma recusa "a um tipo de vinculação inócua ou obsoleta entre os pares escolares" (p. 51), ela seria um indício de tentativa de participação democrática.

"Eu era muito teimoso, bocudo, briguento. (...) Fui expulso na quarta série (...)" (Paulo). A convivência problemática aparece como um grande perturbador na vida dos participantes desta pesquisa. Segundo Paulo e Sandra, a agressividade era uma das reclamações que seus pais mais ouviam de seus professores. Thaís conta que agiu com agressividade física contra uma professora, ao se sentir obrigada a fazer algo com que não concordava. Conforme já abordado na introdução deste trabalho, isso corrobora o argumento de Barkley (2002), que coloca a inabilidade de inibir o comportamento como questão fundamental do TDAH.

Segundo O'Connell (1996), os problemas relacionados à socialização são os mais comuns em crianças desatentas. Então, cuidar dos aspectos afetivos e emocionais é fundamental para que a aprendizagem seja significativa. Sandra revela a validade de ser estabelecida uma boa relação entre o 
professor e os alunos: "O que 'pega' é o professor. Não 'pega' a matéria. Se eu gosto do professor, eu vou; se eu não gosto, já era”.

Durante anos, o autoconhecimento de cada entrevistado tinha sido marcado pelas dificuldades escolares, tanto no que diz respeito ao desempenho nos estudos quanto ao convívio com outros alunos. Talvez por isso, alguns revelam que se tornavam cada vez mais introvertidos e afastavam-se do convívio social, até poucos anos atrás. Para Tonelotto (2002), a percepção que os alunos têm de si pode interferir na aprendizagem. A hiperatividade, segundo Villar e Polaino-Lorente (1994), é associada à auto-estima negativa, por causa da falta de adaptação social. A auto-estima é negativa quando há grande discrepância entre o que se gostaria de ser e aquilo que se pensa que é; a auto-estima é positiva quando a discrepância é pequena. Isso pode ser comprovado também na pesquisa: “(...) eu sempre me vi diferente. Tanto que eu tive depressão por me achar diferente" (Tânia). A entrevistada acredita que se o problema tivesse sido descoberto antes, ela não teria passado por tanto sofrimento.

Eram reais as dificuldades de aprendizagem encontradas por Cláudia, Paulo, Sandra, Tânia e Thaís, mas não por falta de capacidade para aprender. A inquietação e o tempo reduzido de concentração durante as atividades faziam com que eles apreendessem apenas parte do que era ensinado pelos professores. "Eu ia mal na escola, tinha medo de que a professora visse a minha prova para falar que eu tinha errado, porque eu realmente não conseguia prestar atenção na aula" (Sandra). As conseqüências eram poucas anotações no caderno e notas baixas. Os rótulos alusivos ao fracasso escolar, por parte dos colegas, foram inevitáveis: “Ah! A Sandra é burra. "Acreditar no fracasso foi o próximo passo“ Isso me detonava. (...) Aí eu já desisti de tudo" (Sandra). Esse processo de configuração do fracasso escolar é confirmado por Pisecco, Wristers, Swank, Silva \& Baker (2001), que atribui aos problemas comportamentais e de desempenho acadêmico o fato de escolares desatentos terem uma avaliação bastante negativa de si mesmos e, posteriormente, este aspecto ficar consolidado na adolescência.

A fala dos participantes da pesquisa revela uma prática comum nas escolas (e na sociedade): por negar a diversidade, a homogeneização dos sujeitos acaba por promover a exclusão daqueles que não se enquadram aos padrões homogeneizantes. $\mathrm{O}$ processo educativo contribui para a formação das identidades, que depende dos processos de socialização e de ensino-aprendizagem. A resposta que a educação pode oferecer à diversidade e à desigualdade dentro das escolas talvez seja o desafio mais importante enfrentado atualmente pelos sistemas de educação e pelos professores (Cortella, 2003).

\section{Formação de professores: o significado das práticas escolares no desempenho acadêmico de alunos com TDAH}

Os entrevistados fizeram algumas observações relacionadas à formação docente e ao TDAH: desconhecimento dos professores sobre o transtorno; formação de professores críticos; ensino significativo, participativo e questionador; integração entre Educação e outras áreas.

Muitas dificuldades acadêmicas dos participantes da pesquisa são atribuídas ao 
desconhecimento dos professores sobre o transtorno. "Não têm preparo nenhum. Nenhum. Porque o professor não sabe o que é, muitas vezes" (Cláudia). Tânia acredita que sua vida escolar teria sido diferente, se os docentes conhecessem o TDAH: "Então eu acho que se os professores estivessem preparados para ver, eles teriam visto que eu tinha alguma coisa. Eu teria sido diagnosticada antes e não teria passado por tanto sofrimento por que eu passei até chegar na faculdade".

Tão importante quanto a avaliação correta do TDAH, está o seu subdiagnóstico, como alerta Paulo, que é professor e estudante de Psicologia: "Porque tem o caso dessas crianças que não têm a hipercinesia. Têm todos os traços, todas as características, mas essas crianças estão subdiagnosticadas". O entrevistado refere-se ao subtipo de TDAH sem hiperatividade. Pesquisas indicam que o sexo feminino está mais associado ao tipo em que prevalece a desatenção, enquanto os meninos apresentam mais distúrbios de aprendizagem e outros problemas de comportamento escolar. Cantwell e Biederman (conforme citado por Golfeto e Barbosa, 2003) confirmam o subdiagnóstico nos casos do transtorno nas meninas. A justificativa é que elas, geralmente, têm poucos sintomas de agressividade/impulsividade, baixas taxas de transtorno de conduta e alto nível de comorbidade com transtorno de humor e ansiedade.

As experiências dos entrevistados evidenciam que o ensino deve ser significativo, participativo e questionador, deve motivar e envolver os alunos, a fim de que eles não sejam impelidos a buscar, durante as aulas, atividades paralelas que liberem a sua energia e criatividade. Três entrevistados sugerem a necessidade de formação crítica do professor, formação de pesquisadores que busquem informações sobre os problemas que surgem no cotidiano da profissão. Benczik e Bromberg (2003) criticam o mecanismo do sistema Educacional que, tradicionalmente, concentra os objetivos de ensinoaprendizagem no aspecto cognitivo. Além disso, esses objetivos costumam ser os mesmos para todos os alunos e o ponto de referência é o aluno padrão. "Na metodologia tradicional, o professor transmite a informação acabada aos alunos, a comunicação encontra-se centrada no professor e é unidirecional" (p. 207).

A necessidade de muita motivação para desenvolver determinadas atividades é a explicação dada pelos entrevistados para justificar a recusa à realização de alguma proposta, da maneira como os professores a impõem. Fazer o que gosta, ou o que tem facilidade, parece a solução para os problemas relacionados ao TDAH. Talvez este seja um dos grandes desafios colocados aos educadores: permitir que, a partir de suas preferências, o aluno inicie um processo de aprendizagem, enquanto sejam elaborados mecanismos para que ele aprenda aquilo de que ainda não gosta, mas que lhes parece necessário. Mattos e cols. (2003) alertam para o fato da existência de situações específicas em que o indivíduo com TDAH consegue manter níveis adequados de concentração durante um tempo maior. Entretanto, em geral, esses momentos podem ser entendidos "como 'ilhas' isoladas num oceano de dificuldades atentivas gerais, e habitualmente envolvem situações muito estimulantes para o indivíduo" (p. 223). De acordo com as orientações do DSM-IV (1994), crianças com TDAH 
apresentam dificuldades em manter a atenção até mesmo em tarefas ou atividades lúdicas.

Quando questionada sobre as transformações que poderiam ter ocorrido em seu desempenho escolar, caso os professores conhecessem o transtorno, Thaís responde: "a hiperatividade era muita e acho que isso teria mudado muito pouco". Essa fala aponta para a importância de se repensar as práticas escolares e de o professor compreender quando deve buscar o auxílio de outros profissionais para melhor encaminhar o processo de ensino e aprendizagem de alunos com TDAH. Tânia acredita na divisão de tarefas ao dizer que, se o professor tiver boa formação para trabalhar com o TDAH, poderá fazer um encaminhamento adequado a outros profissionais e somar esforços para contornar os problemas: "Fazendo um trabalho junto com um psiquiatra, com psicólogo, eu acho que já é meio caminho andado".

O professor é muito importante na Avaliação do transtorno, pelo tempo de convivência com os alunos. Entretanto, não se deve delegar a ele a tarefa de fazer o diagnóstico. O professor pode avaliar as dificuldades apresentadas pelos alunos e, se for o caso, solicitar que a família procure ajuda especializada. Deve também relatar aos especialistas as suas percepções sobre o desempenho acadêmico ou comportamental dos alunos, bem como traçar estratégias de ação docente, a partir do que for constatado pelos profissionais competentes. Apesar das evidências de que o desempenho escolar de alunos com TDAH depende, em grande parte, dos professores, apoiadas em Aquino (2003), reforça-se que há, atualmente, uma tendência de se exigir do professor o cumprimento de inúmeros papéis: familiar, clínico, assistente social, nutricionista - uma espécie de "polivalência funcional a ele atribuída, redundando, muitas vezes, numa apropriação messiânica, porém cambaleante, do lugar docente" (p. 23).

$\mathrm{Na}$ pesquisa, as práticas escolares, responsabilidade imediata dos professores, ocuparam lugar de destaque na discussão e apontaram caminhos para a reflexão sobre a formação docente e o trabalho com alunos que apresentam instabilidade da atenção, impulsividade e/ou hiperatividade. A influência do professor no desempenho escolar dos alunos apareceu de forma relevante na fala dos entrevistados, que enfatizaram não apenas a importância da formação técnica do professor, como também a valorização da diversidade humana. Entendemos que, além disso, há determinantes estruturais e organizacionais a serem considerados no processo pedagógico, por exemplo, as condições de trabalho dos profissionais da educação e as condições de ensino oferecidas aos alunos. Para Emílio (2004), alguns cuidados, como o número de alunos por turma e a quantidade de alunos com problemas de aprendizagem ou de comportamento em cada classe, quando observados, podem possibilitar a interação entre os envolvidos no processo de ensino-aprendizagem e o atendimento às necessidades de cada um. A autora, ao final de sua investigação sobre o cotidiano escolar, ressalta que, em certas situações, a busca de parcerias com outros profissionais - médicos e psicólogos - que possam auxiliar a família e o aluno a lidar com suas dificuldades, é imprescindível "para que a escola possa desempenhar bem o seu papel e assumir as responsabilidades que lhe cabem" (pp. 221-222). 


\section{Considerações Finais}

A pesquisa permite afirmar que o êxito na administração dos problemas decorrentes do TDAH está relacionado à adoção de medidas que incluam um novo direcionamento na Educação. É fundamental que o trabalho Educacional seja integrado com compreensão, determinação, perseverança e paciência. Mas, somente isso não basta.

Por enquanto, a melhor medida de contorno das dificuldades encontradas pelos alunos com TDAH em sala de aula parece ser a mudança de postura do professor, no sentido de tornar o ensino mais participativo, solidário, democrático, criativo e reflexivo, ao mesmo tempo em que as políticas educacionais devem contribuir para a promoção social de todos, em sua diversidade.

A pesquisa mostra a importância de os cursos de formação de professores no Ensino Superior contemplarem a reflexão sobre as práticas escolares enraizadas no dia-a-dia da escola. A formação docente, compromissada com as transformações sociais, ao apontar para a urgência de se colocarem as práticas escolares no centro das discussões educacionais, poderá abarcar os problemas relacionados ao transtorno, em suas diferentes dimensões.

No entanto, Sacristán (1995) atenta para o fato de o discurso pedagógico dominante hiperresponsabilizar os professores em relação à prática pedagógica e à qualidade de ensino, "situação que reflete a realidade de um sistema escolar centrado na figura do professor como condutor visível dos processos institucionalizantes de educação" (p. 64).
A condição para a melhoria da qualidade da Educação é, muitas vezes, projetada sobre a figura do professor. A explicação deve-se, de certo modo, a uma deformação profissional, a uma ocultação ideológica das casualidades reais dessa prática, ou ainda ao fato de "esta atitude encobrir o baixo estatuto social da profissão docente" (p. 64). Para o autor, a atuação dos professores é acentuada tanto pelo discurso pedagógico quanto social. A prática docente está relacionada aos professores, mas não depende unicamente deles. É preciso, a partir de condicionantes políticos e históricos, compreender as ligações entre os professores e a prática, bem como o princípio da relativa "irresponsabilidade" dos professores em relação a ela. Por isso, entendese ser necessário refletir sobre a teia de significados das práticas escolares, que são o contexto imediato do trabalho pedagógico, em suas diferentes dimensões, ou, na definição de Sacristán (1995), refletir sobre o "sistema de práticas educativas aninhadas" (práticas institucionais, organizativas e didáticas). O conceito de prática deve ser alargado, saindo dos limites do domínio metodológico e do espaço escolar, pois a prática é mais abrangente que as ações dos professores: "A prática profissional depende de decisões individuais, mas rege-se por normas coletivas adotadas por outros professores e por regulações organizacionais" (p. 71).

Quanto às formas de interpretação do TDAH, entende-se que se deva ultrapassar a discussão dicotômica sobre quem seriam os culpados pelo desempenho escolar dos alunos com o transtorno geralmente, ora a escola ora o aluno -, buscando a superação da questão, a partir da compreensão de sua complexidade. Além disso, no atual contexto educacional brasileiro há muitos fatores que 
contribuem para um baixo rendimento escolar, como superlotação das salas de aula, defasagem na formação de professores, má remuneração financeira, concentração dos objetivos de ensinoaprendizagem no âmbito cognitivo, aluno padrão como ponto de referência, os mesmos objetivos para todos os alunos (Benczik \& Bromberg, 2003).

Para a superação das barreiras que oferecem obstáculos à aprendizagem, e visando à formação de identidade dos alunos de forma mais humanitária, o trabalho dos profissionais da área da educação precisa ser coletivo e estar articulado com políticas sociais e econômicas, pois exigem mudanças profundas em atitudes, crenças e práticas para assegurar que todos os alunos, sem qualquer discriminação, tenham as mesmas oportunidades de aprendizagem e que possam desenvolver plenamente suas capacidades.

\section{Referências}

Alberti, V. (2004). Manual de história oral. (2 $2^{\mathrm{a}}$ ed.) Rio de Janeiro: FGV.

Aquino, J. G. (2003). Indisciplina: o contraponto das escolas democráticas. São Paulo: Moderna.

Associação Americana de psiquiatria (1994). Manual diagnóstico e estatístico de transtornos mentais, DSMIV. (4 ${ }^{\text {a }}$ ed.). Porto Alegre: Artes Médicas Sul.

Barkley, R. A. (1997). ADHD and the nature of self control. New York: Guilford Press.

Barkley, R. A. (2002). Transtorno de Déficit de Atenção/Hiperatividade. Porto Alegre: Artmed.
Benczik, E. B. P., \& Bromberg, M. C. (2003). Intervenções na escola. Em L. A. Rohde \& P. Mattos (Orgs.), Princípios e práticas em transtorno de déficit de atenção/hiperatividade (pp. 199-218). Porto Alegre: Artmed.

Cortella, M. S. (2003). Diversidade e cidadania. Em L. G. Arelaro \& S. Silva (Orgs.), Diversidade e exclusão: a sensibilidade de quem as vive [Vídeo]. São Paulo: Produtora de Vídeos. (Coordenadora geral: Lisete Regina Gomes Arelaro)

Emílio, S. A. (2004). O cotidiano escolar pelo avesso: sobre laços, amarras e nós no processo de inclusão. Tese de Doutorado, Faculdade de Psicologia, Universidade de São Paulo, São Paulo.

Golfeto, J. H., \& Barbosa, G. A. (2003). Epidemiologia. Em L. A. Rohde \& P. Mattos (Orgs.), Princípios $e$ práticas em transtorno de déficit de atenção/hiperatividade (pp. 15-33). Porto Alegre: Artmed.

Hallowell, E. M., \& Ratey, J. J. (1999). Tendência à distração: identificação e gerência do distúrbio de Déficit de atenção (DDA) da infância à vida adulta. (A. Carvalho, trad.). Rio de Janeiro: Rocco. (Trabalho original publicado em 1994).

Kuenzer, A. Z. (2002). O que muda no cotidiano da sala de aula universitária com as mudanças no mundo do trabalho? Em S. Castanho \& M. E. Castanho (Orgs.), Temas e textos em metodologia do ensino superior $\left(2^{\mathrm{a}}\right.$ ed., pp. 15-28). Campinas: Papirus.

Mattos P, Abreu, P. B., \& Grevet, E. (2003). O TDAH no adulto: dificuldades diagnósticas e de tratamento. Em L. A. Rohde \& P. Mattos (Orgs.), Princípios e práticas em transtorno de déficit de atenção/hiperatividade (pp. 219-236). Porto Alegre: Artmed. 
Mattos, P., Saboya, E., Kaefer, H., Knijnik, M. P., \& Soncini, N. (2003). Neuropsicologia do TDAH. Em L. A. Rohde \& P. Mattos (Orgs.), Princípios e práticas em transtorno de déficit de atenção/hiperatividade (pp. 6373). Porto Alegre: Artmed.

O’Connell, K. L. (1996). Attention deficit hyperactivity disorder. Pediatrics Nurses, 22(1), 30-33.

Pisecco, S., Wristers, K., Swank, P., Silva, P. A., $\&$ Baker, D. B. (2001). The effect of academic selfconcept on ADHD and antisocial behaviors in early adolescence. Journal of Learning Disabilities, 34(5), 450-461.

Sacristán, J. G. (1995). Consciência e acção sobre a prática como libertação profissional dos professores. Em A. Nóvoa (Org.), Profissão Professor (pp. 64-91). Portugal: Porto Editora, LDA.
Tonelotto, J. M. F. (2002). Autopercepção de crianças desatentas no ambiente escolar. Revista Estudos de Psicologia, 19(3), 31-42.

Tonelotto, J. M. F. (2003). Aspectos acadêmicos e sociais do transtorno do déficit de atenção. Em S. M. Ciasca (Org.), Distúrbios de aprendizagem: proposta de avaliação interdisciplinar (pp. 203-220). São Paulo: Casa do Psicólogo.

Villar, I. O., \& Polaino-Lorente, A. (1994). Estilos Atribucionales y autoestima en hiperatividad infantil. Revista de Psicología Geral Y Aplicada, 47(4), 461-466.

Recebido em: 28/09/2006

Revisado em: 23/11/2007

Aprovado em: 12/01/2008

Sobre as autoras:

Maria das Graças Faustino Reis (grafareis@uol.com.br) - Mestre em Educação pela PUC-Campinas

Rua Antônio Luiz Russi, 54, Pq. da Represa, Jundiaí (SP), CEP: 13214-570.

Dulce Maria Pompêo de Camargo (dpompeo@mpc.com.br) - Doutora em Educação pela UNICAMP.

Rua Américo de Campos, 380, Cidade Universitária, Campinas (SP), CEP 13083-040.

Nota das autoras: Origem do trabalho: Dissertação de Mestrado, PUC-Campinas, 2006. 